\title{
Training nursing home staff to improve residents' end-of-life care: design and baseline findings from a randomized controlled trial
}

\author{
Pauli J. Lamppu ${ }^{1} \cdot$ Jouko Laurila $^{1} \cdot$ Harriet Finne-Soveri ${ }^{2} \cdot$ Marja-Liisa Laakkonen $^{3} \cdot$ Hannu Kautiainen $^{1}$. \\ Kaisu H. Pitkälä ${ }^{1,4}$
}

Received: 15 March 2019 / Accepted: 29 April 2019 / Published online: 21 May 2019

(c) The Author(s) 2019

\section{Key summary points}

Aim We present the design, intervention, baseline findings and feasibility of a randomized, controlled trial examining the effectiveness of staff training in palliative care on nursing home residents' hospitalizations and health-related quality-of-life. Findings Most staff members participated in the training sessions and they gave good feedback. Our patient groups are fairly well balanced in their characteristics.

Message If our further trial shows patient-related benefits, we will have a well-defined model for improving palliative care in nursing homes.

\begin{abstract}
Purpose We aim to describe the design, educational intervention, baseline findings and feasibility of our training intervention. Our trial will aim to improve the residents' health-related quality of life (HRQOL) and to reduce unnecessary hospitalizations. Methods We recruited 340 residents from 20 nursing home wards in Helsinki, and they were randomized into intervention and control groups. At baseline, all the participants were assessed for demographics, medical history, medication, HRQOL, symptoms, hospitalizations, advance care plans, and proxies' satisfaction with care. The staff in the intervention wards were offered four 4-h educational sessions on the principles of palliative care (advance care planning, the adverse effects of hospitalizations, symptom management, communication, giving support to proxies and challenging situations). The sessions were based on constructive learning methods and patient cases.

Results The mean age of residents was 84 years and $76 \%$ were women. The intervention and control groups did not differ with respect to demographics, terminal diseases, comorbidities, nutritional status, cognition or the use of palliative medication. However, the control residents were more likely to be bed-bound and to have a do-not-resuscitate order on their medical chart. Of about 180 staff members, 132 completed the educational intervention. The discussions in the training sessions were lively and the participants gave an overall rating of $4.6 / 5$ for the education.

Conclusions We have successfully randomized nursing home wards in this trial and completed staff training with very positive feedback. If our trial shows resident-related benefits, we will have a well-defined model for improving palliative care in nursing homes. The study was registered in the Australian New Zealand Clinical Trials Registry under the intervention code: ACTRN12617001040358.
\end{abstract}

Kaisu H. Pitkälä

kaisu.pitkala@helsinki.fi

1 Department of General Practice and Primary Health Care, University of Helsinki, PO Box 20, 00014 Helsinki, Finland

2 National Institute of Health and Welfare, Helsinki, Finland

3 Department of Social Services and Health Care, Geriatric Clinic, Helsinki Hospital, Helsinki, Finland

4 Unit of Primary Health Care, Helsinki University Hospital, Helsinki, Finland 
Keywords Palliative care $\cdot$ Advance care planning $\cdot$ Training $\cdot$ Nursing home $\cdot$ Randomised controlled trial

\section{Introduction}

Developing palliative care and end-of-life care in nursing homes and assisted living facilities has become a topic of increasing interest $[1,2]$. It has been suggested that enhanced advance care planning (ACP), the use of advance directives (ADs) and early communication about care preferences yield better quality end-of-life care and concordance of care with residents' preferences, and it may also decrease the incidence of hospital transfers [3, 4]. Interventions enhancing $\mathrm{ACP}$ and ADs have used various means such as standardized $\mathrm{AD}$ forms [5], external facilitators who discuss issues with residents and their proxies [6,7], and training staff as well as residents and their surrogates in end-of-life care $[8,9]$.

Hospitalizations of nursing home residents are abundant even if the health benefits appear to be questionable and they are always burdensome for older residents. Among the ill-effects are delirium, the use of restraints, pressure ulcers, the use of feeding tubes and functional impairment [10-13]. Despite guidelines to the contrary, most older people living in long-term care in Finland die in hospitals and not in their own nursing homes [14].

There have been several trials examining various interventions to promote ACP. ACP seems to decrease the need for hospital care [2] and is associated with a reduction in emotional symptoms related to dying [15]. However, few studies are conducted in nursing home settings [16]. There have been randomized trials investigating how to avoid burdensome hospitalizations among nursing home residents. It is suggested in a few early controlled trials that employing nurse care practitioners [7] and staff training [5, 9, 17] may reduce the incidence of hospitalization. However, later studies have not replicated these findings [18]. The INTERACT project, the aim of which was to reduce hospital transfers, showed a clear reduction following the implementation of a quality-improvement initiative involving staff training, decision-making aids and continuing support [19]. However, these benefits were only observed in the initial feasibility study and were not replicated in the follow-up studies [20-22].

It is reported in several studies that educational interventions focusing on palliative care targeted at nursing home staff may encourage the completion of ADs, enhance discussions on end-of life care and improve staff knowledge, but most studies only report on surrogate rather than patientrelated outcomes [23]. We will investigate whether an educational intervention could benefit nursing home patients with respect to their quality-of-life. In doing so, we are carrying out a cluster-randomized educational trial examining whether offering training in palliative care to staff in nursing homes would (1) improve the residents' health-related quality of life (HRQOL), and (2) reduce burdensome hospitalizations during a 2-year follow-up period, compared to a control group in normal care. The secondary endpoints include pain, other symptoms and satisfaction among proxies. In this article, we describe the design of the study, the intervention and measures in detail, baseline findings of the residents and the feasibility and feedback for the training.

\section{Methods}

\section{Study design and participants}

This is a single-blinded cluster-randomized trial in which nursing home and assisted living facility wards in Helsinki were randomized into two groups: the staff in the intervention were offered training in palliative and end-of-life care over four afternoons, whereas the staff in the control wards would receive such training after the trial. Assisted living facilities in Finland are like traditional nursing homes offering around-the-clock nursing care but are more home-like. Both types of facility are nurse led; physicians are in a consulting role and the nurses present patients' problems to the physician as needed.

The inclusion criteria for participation were:

1. being Finnish-speaking;

2. being a permanent resident in a nursing home or assisted living facility in the city of Helsinki;

3. having at least one predefined severe disease or condition that was likely to have a less than 12-month prognosis (severe dementia, cancer, heart failure, COPD, renal failure, severe disability, other terminal disease);

4. being a volunteer and able to give informed consent; in cases of moderate to severe cognitive impairment (CDR $2-3)$, the consent was provided by the closest proxy.

\section{Randomization}

We screened all communal nursing home wards in Helsinki using RAI (Resident assessment instrument) measurement data from MDS (Minimum Data Set) [24]. MDS is a widely adopted international scoring system used in almost all nursing homes in Finland. We paired nursing home wards of a similar case mix and then randomly assigned one from each pair to either the intervention or control group. We used computer-generated randomly allocated numbers received by telephone from a randomization center. 


\section{Measures}

Baseline information for both study groups was assessed between November 2017 and January 2018. Complementing the demographic data, we collected active diagnoses from patient records and computed Charlson comorbidity indexes [25]. The health status and probable prognosis of the residents were assessed according to the diagnoses, malnutrition and disability. We evaluated the most severe terminal condition for each participating resident. Severe dementia was assessed as a score 3 on the Clinical Dementia Rating scale (CDR) [26] and under 11 points on the Mini-Mental State Examination (MMSE) [27].

Nutritional status was determined according to the MNA (Mini-nutritional assessment) [28], and each subject was categorized as having good nutrition (24-30 points), being at risk of malnutrition (17-23.5) or being malnourished $(<17)$. The residents' height and weight were measured and their body mass index (BMI) was calculated accordingly.

The reporting of medications used by the residents is based on the Anatomical Therapeutic Chemical (ATC) classification endorsed by the World Health organization [29]. Here, we report on those that are commonly used in palliative care: opioids N02A, paracetamol (N02BE01) selective and nonselective nonsteroidal anti-inflammatory drugs (NSAID; M01A), antipsychotics N05A, anxiolytics N05B, antiemetics and medicine used for nausea or death rattle A04A or A03A [30].

Data on earlier hospitalizations were retrieved from the residents' medical records. We report here on the proportion of those who were hospitalized during the year before the study began.

Each participant was assessed for a variety of symptoms using Edmonton symptom assessment system (ESAS) [31]. Pain was also evaluated separately on the Pain Assessment in Advanced Dementia (PAINAD)-scale [32].

We used the $15 \mathrm{D}$-instrument to measure health-related quality of life (HRQOL) [33]. It evaluates 15 different dimensions of HRQOL and can be either patient reported or evaluated by means of observation. The instrument has proved capable of detecting change in nursing home settings. We omitted the dimension of sexual function in line with previous practice [34]. Psychosocial well-being (PWB) was assessed on six questions measuring the different dimensions [35]. The extent to which proxies were satisfied with care was assessed using the Satisfaction with Care at the End-ofLife in Dementia scale (SWC-EOLD) [36] presented for the proxies. The range of the scale is from 10 to 40, with higher score indicating higher satisfaction.

Research nurses were responsible for gathering the baseline information from all the assessed residents, those with limited communicative capabilities being assessed with their nurses or proxies when feasible. The research nurses were blind to the information on random allocation. The follow-up assessments will be made at 6 and 12 months from the intervention. In addition, all use of health care services will be retrieved from medical and central records at the 24-month follow-up.

\section{Educational intervention}

Nurses and physicians in the intervention wards were given training over four afternoons that included the basics of good palliative care, advance care planning, good symptom management, communication skills, tailoring end-of-life care, supporting relatives, and confronting challenging situations in end-of-life-care. The theoretical framework for designing the intervention was based on adult learning [37], reflective learning [38], problem-based learning [39] and constructive learning [40]. The nurses and physicians in the intervention wards were sent a questionnaire regarding their learning needs and wishes before the training started. They were also asked to suggest topics for the training, and to describe the challenges associated with palliative care in their everyday work and the kind of support they received. Of the 132 staff members participating in the training, 45 responded to this pre-training questionnaire. The topics acknowledged as learning needs were "confronting patients' and their relatives anxiety and demands" (89\%), "breaking bad news" (87\%), "delirium" (82\%), "advance care planning" (80\%), "futile treatments at the end-of-life" (80\%) and "assessment and management of pain" (80\%). The intervention education was constructed according to the expressed needs and wishes. We assumed that the motivation for training would be highest if the topics were relevant to the staff members.

Each session was led by a geriatrician from the study team, namely: KP, ML, JL or HF who have long experience working and doing research both in nursing homes and palliative care. Table 1 summarizes the aims, contents and methods of the intervention. We also gathered post-training feedback to help us judge its feasibility: we asked several questions concerning how they felt the intervention had succeeded, assessed on a Likert scale ranging from 1 to 5 (poor ...excellent). Free-text items were also included.

\section{Outcome measures in trial analyses}

The primary outcome measures will be change in HRQOL according to $15 \mathrm{D}$ [33] and the number of hospital days over 24 months from baseline. Secondary outcome measures will include change in symptoms according to ESAS [31] and PAINAD [32]. We will measure the change in PWB [35]. In addition, we will count the number of hospital admissions and care transitions, report total health-care use and costs, and assess proxies' satisfaction according to SWC-EOLD [36]. Finally, we will collect data on advance care plans 


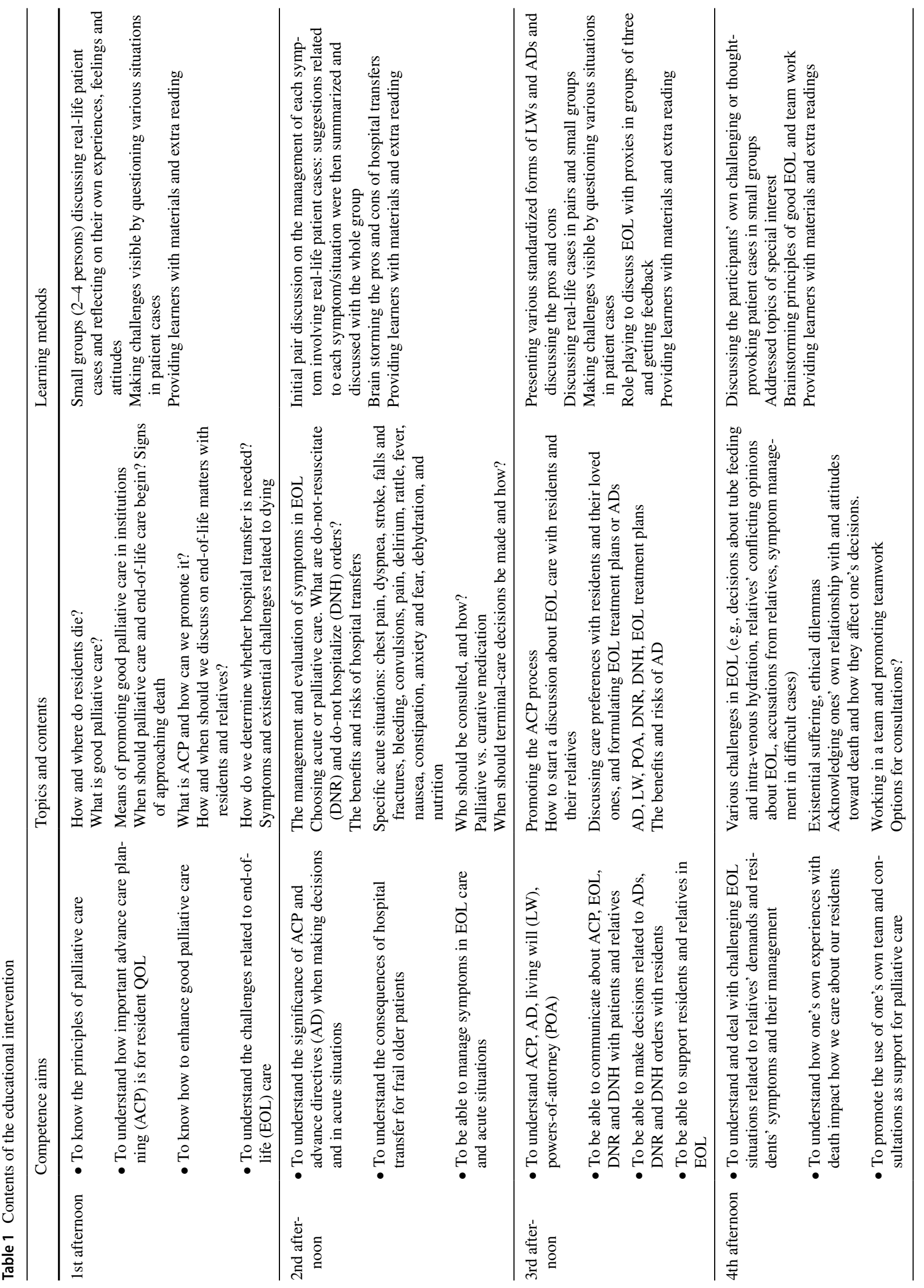


during the 12-month follow-up and report mortality during the follow-up period.

\section{Statistical analysis}

The power calculation was based on the $15 \mathrm{D}$ measure (HRQOL). The sample size was calculated on the assumption of detecting a clinically significant difference of 0.004 in $15 \mathrm{D}$ scores between the intervention and the control groups. With an estimated standard deviation of 0.01 , a type-I error of $0.05 \%$ and $80 \%$ power, 120 patients would be needed in each group. Our power calculation hypothesized a $20 \%$ dropout; therefore, we aimed to recruit at least 150 participants in each group.

We used the $t$ test, Mann-Whitney, Chi square or Fischer exact test to make statistical comparisons between the groups. In cases of violation of the assumptions (e.g., non-normality), we used a bootstrap-type test. We assessed the normality of the variables was by means of the Shapiro-Wilk $W$ test. We assigned missing values for the SWCEOLD scale by means of multiple imputation by chained equations [41] using the ice command in Stata [42]. Stata 15.1 (StataCorp LP, College Station, TX, USA) was used for the analysis.

\section{Results}

Our pair-matched wards had 494 residents at the start of the recruitment process on 1 September 2017. Baseline assessment was performed on the qualifying 340 residents who gave their informed consent. After randomization, our intervention group consisted of 159 and the control group of 181 residents living in 20 nursing home and assisted living facility wards. More details are given in Fig. 1.

\section{Baseline findings}

Average age of the residents was 84 years and $75 \%$ were women. There were no significant differences between the two groups in educational background, nutritional status, burden of disease, percentage of inclusion criteria diseases, MMSE, CDR, PWB or 15D.

At baseline, there were more residents with a do-notresuscitate (DNR) order in their medical charts in the control group than in the intervention group $(95.0 \%$ vs. $69.6 \%$, $P<0.001)$. Furthermore, those in the control group were slightly less independent in terms of moving and were more likely to be bed-bound. Those in the intervention group were evaluated as experiencing slightly more pain, although there was no notable difference in the use of pain medication between the two groups: in both, $28 \%$ were on regular opioid medication and about half were on paracetamol. Earlier hospitalizations were equally common in both groups, about one-third having been hospitalized during the previous year (see Table 2).

\section{Feasibility of the intervention}

Of the total 180 estimated staff members, 132 completed the intervention training, representing $74 \%$ of the total staff, including all five physicians working in the wards. We gathered both numerical and free-text feedback from all participants after the last intervention session. Overall, the feedback was very positive (mean $4.6 / 5$, range $3-5$ ). This high score reflected the lively discussion and the enthusiasm the participants showed during the sessions. The freetext feedback was almost entirely positive. There were three recurring themes to which the staff attached importance in free-text comments: (1) avoiding hospital transfers, (2) promoting advance care planning and communication with relatives, and (3) practical end-of-life care and medication. The possible harmfulness of hospitalization seemed to be deeply thought-provoking and novel notion to many of the participants. The staff members also evaluated how effectively they had learned about various aspects of end-of-life care: these learning objectives were reached with a mean score of $4.3 / 5$ (range 4.0-4.6) (see Table 3 for more information).

\section{Discussion}

We successfully randomized nursing home and assisted living wards and their 340 participating residents into intervention and control groups. According to the baseline analysis, the groups seem to be well balanced along most dimensions of health and well-being we evaluated. However, DNR orders were more common in the control wards than in the intervention wards prior to the intervention. We succeeded in training $74 \%$ of the staff and all the physicians in our intervention. The training was well received and provided novel insights for the trainees.

Our study has several methodological advantages compared to previous research on this topic. Cluster-randomized designs are rarely used in studies focusing on educational needs in nursing homes [23]. We adopted a rigorous randomized design to ensure that the confounders would be randomly allocated to the intervention and the control groups. To prevent contamination of the intervention, we used cluster randomization. The design of the intervention trial allowed us to optimize the sample size, pair match the wards for case mix, and use more rigorous methods in gathering data. Two thoroughly trained and experienced research nurses blinded to the group assignment gathered the data, with a view to ensuring reliability and minimizing bias. 
Fig. 1 Flowchart of the trial

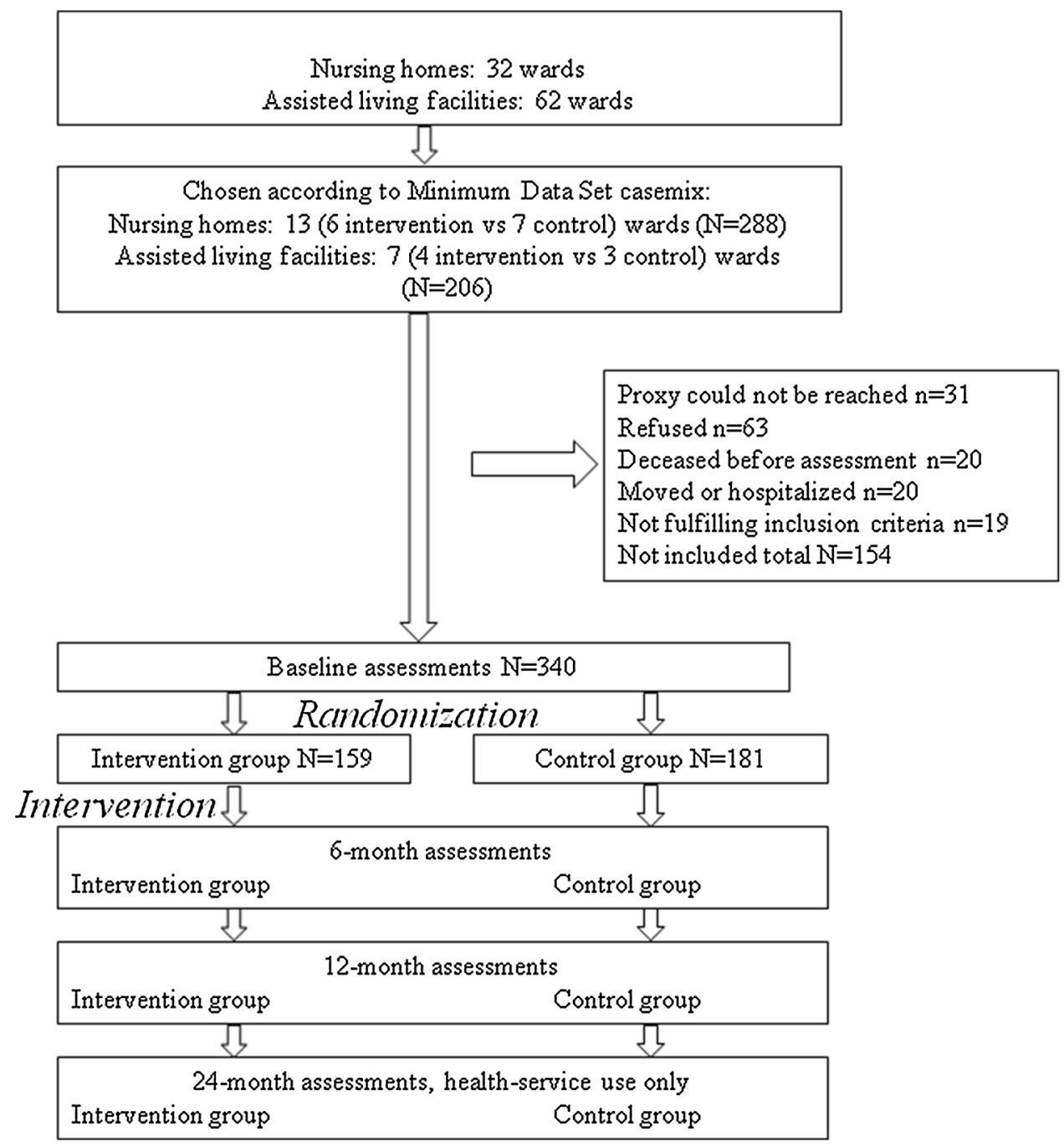

There are several limitations and threats to be considered. The intervention and the control groups differed significantly in some characteristics such as DNR orders, mobility, and pain. These differences should be adjusted for in analyses of changes in the groups during the follow-up. Other threats relate to the real-life setting of the study. Wards of this type typically have high staff turnover, which our participating staff members also confirmed. A high staff turnover rate is a typical diluting factor in this setting. Given that the wards are physically close to one another, it is also possible that a change of workplace during follow-up would cause contamination between the two study groups. There has recently been an increasing tendency on the national level to develop palliative care and advance care planning in Finnish nursing homes and assisted living facilities, and it is quite likely that some of the staff in the control wards had also recently been involved in other projects working toward similar goals as our intervention. Even the increasing public attention to palliative care could easily dilute the effect of our intervention in the follow-up. The marked difference in DNR orders between the intervention and the control groups could well be a sign of previous educational interventions.

We succeeded in persuading a large proportion of the staff to participate, including all the physicians and most of the registered nurses. It is, therefore, likely that we managed to educate staff members who had been found in previous studies [43] to be opinion leaders, strongly influencing the decision-making cultures of the wards. Decision making in nursing homes on end-of-life care has previously been shown to be based only to some extent on factual knowledge, and to be strongly based on the attitudes and the culture of the working environment [44, 45]. We considered it important to include co-operative and emotion-evoking components and reflection in the training. The good feedback we received implies good feasibility, and the free-text comments on the importance and perceived novelty of avoiding hospitalization suggest the potential for attitude change in the intervention wards that might later result in reduction in avoidable hospitalizations. 
Table 2 Baseline findings of the residents

\begin{tabular}{|c|c|c|c|}
\hline Baseline characteristics & Intervention $(N=159)$ & Control $(N=181)$ & $P$ value \\
\hline Mean age, (SD) & $83.5(7.5)$ & $84.6(7.8)$ & 0.14 \\
\hline Women, $n(\%)$ & $120(75.5)$ & $138(76.2)$ & 0.87 \\
\hline Education $<8$ years, $n(\%)$ & $76(48.8)$ & $95(52.4)$ & 0.53 \\
\hline Main inclusion criteria, $n(\%)$ & & & 0.75 \\
\hline Severe dementia & $96(60.4)$ & $118(65.2)$ & \\
\hline Cancer & $12(7.5)$ & $10(5.5)$ & \\
\hline Heart failure & $23(14.5)$ & $20(11.0)$ & \\
\hline COPD & $0(0)$ & $2(1.1)$ & \\
\hline Renal failure & $2(1.3)$ & $2(1.1)$ & \\
\hline Severe disability & $21(13.2)$ & $23(12.7)$ & \\
\hline Other terminal condition & $5(3.1)$ & $6(3.3)$ & \\
\hline $\mathrm{CDR}, n(\%)$ & & & 0.62 \\
\hline $0-1$ & $39(24.5)$ & $37(20.5)$ & \\
\hline 2 & $35(22.0)$ & $45(24.9)$ & \\
\hline 3 & $85(53.5)$ & $99(54.7)$ & \\
\hline MMSE, mean (SD) & $10.0(9.5)$ & $8.5(9.0)$ & 0.17 \\
\hline MNA, $n(\%)$ & & & 0.81 \\
\hline Malnourished $<17$ & $26(16.4)$ & $34(18.8)$ & \\
\hline At risk of malnutrition $17-23.5$ & $113(71.1)$ & $123(68.0)$ & \\
\hline Well-nourished $>23.5$ & $20(12.6)$ & $24(13.0)$ & \\
\hline Needs assistance in ADL, $n(\%)$ & $133(83.6)$ & $164(90.7)$ & 0.054 \\
\hline Mobility, $n(\%)$ & & & 0.014 \\
\hline Needs assistance in walking & $22(13.8)$ & $32(17.7)$ & \\
\hline Bed-bound & $72(45.3)$ & $102(56.4)$ & \\
\hline Charlson comorbidity index, mean (SD) & $2.8(1.5)$ & $2.8(1.7)$ & 0.25 \\
\hline Mean number of medications, (SD) & $10.0(4.0)$ & $9.2(3.7)$ & 0.15 \\
\hline Mean number of "pro re nata" medications (SD) & $4.8(2.4)$ & $5.1(2.8)$ & 0.67 \\
\hline Pain medication, $n(\%)$ & $103(64.8)$ & $123(68.0)$ & 0.54 \\
\hline Opioid & $44(27.7)$ & $51(28.2)$ & 0.92 \\
\hline Weak opioid & $32(20.1)$ & $38(21.0)$ & 0.84 \\
\hline Strong opioid & $13(8.2)$ & $13(7.2)$ & 0.73 \\
\hline Paracetamol & $76(47.8)$ & $101(55.8)$ & 0.14 \\
\hline NSAID & - & - & na \\
\hline Pregabalin/gabapentin & $15(9.4)$ & $16(8.8)$ & 0.85 \\
\hline Psychotropic medication, $n(\%)$ & $98(47.3)$ & $108(52.7)$ & 0.79 \\
\hline Antipsychotic & $42(26.4)$ & $41(22.7)$ & 0.42 \\
\hline Anxiolytics & $20(12.6)$ & $17(9.4)$ & 0.35 \\
\hline Antiemetic medication, $n(\%)$ & $1(0.6)$ & $3(1.7)$ & 0.38 \\
\hline Opioid as pro re nata, $n(\%)$ & $53(33.3)$ & $68(37.6)$ & 0.58 \\
\hline Psychotropic as pro re nata, $n(\%)$ & $93(58.5)$ & $93(51.4)$ & 0.19 \\
\hline Hospitalized during the previous year, $n(\%)$ & $56(35.2)$ & $66(36.5)$ & 0.81 \\
\hline 15D-score, mean (SD) [0-1] & $0.596(0.098)$ & $0.577(0.103)$ & 0.076 \\
\hline PWB, mean (SD) [0-1] & $0.72(0.024)$ & $0.71(0.22)$ & 0.95 \\
\hline PAINAD, mean (SD) [0-10] & $0.58(1.1)$ & $0.36(0.78)$ & 0.037 \\
\hline ESAS, mean (SD) [0-110] & $10.4(8.2)$ & $9.88(7.76)$ & 0.58 \\
\hline SWC-EOLD, mean (SD) [10-40] & $29.0(4.8)$ & $28.1(5.0)$ & 0.13 \\
\hline Do-not-resuscitate order, $n(\%)$ & $110(69.6)$ & $171(95.0)$ & $<0.001$ \\
\hline
\end{tabular}

The differences between the groups were tested with the $t$ test, Mann-Whitney, a bootstrap-type test, Chi square or Fischer exact test

$S D$ standard deviation, $C O P D$ chronic obstructive pulmonary disease, $C D R$ clinical dementia rating [25], MMSE Mini-Mental State Examination [26], MNA mini-nutritional assessment [27], 15D 15-dimensional health-related quality-of-life instrument [32], $P W B$ psychological well-being [34], PAINAD pain assessment in advanced dementia scale [31], ESAS Edmonton Symptom Assessment System [30], ADL activities of daily living [23], SWC-EOLD satisfaction with Care at the End-of-Life in Dementia scale [35] 
Table 3 Participants' $(n=132)$ self-evaluation of their achievement of the educational objectives

Learning objective

Achieving objective, average numerical score $(1-5)$

Making an end-of life care plan or advance care plan in collaboration with the resident and/or his/her proxy

Evaluating and treating end-of-life symptoms

Knowledge of good palliative and symptom care

Communication skills related to death, palliative care and supporting relatives

4.1

Understanding the consequences of hospital transfers

4.6

Treating acute symptoms and complications

4.1

Understanding the significance of advance planning for solving acute problems

4.4

Understanding the concepts of advance directives, end-of-life care planning and power-of-attorney

4.4

Managing various demanding situations in end-of-life care

Understanding how one's own experiences and attitudes toward death and dying influence how one treats residents

4.4

Using one's own team and consultations to support palliative care

4.4

Activating learning methods and reflection based on constructive learning theory have previously been shown to result in effective learning in adult education in the medical field [46]. The intervention was designed to be light and suitable for real-life use. We also strived for a well-outlined intervention to enable replication and allow further comparisons between different educational interventions. If our further follow-up shows resident-related benefits, we will have significantly enhanced current knowledge about the planning of future quality-improvement projects related to nursing home residents' end-of-life needs.

Acknowledgements Open access funding provided by University of Helsinki including Helsinki University Central Hospital.

Funding This study was supported by Helsinki University Hospital. The funding sources had no role in the design and conduct of the study; in the collection, analysis, and interpretation of the data; or in the preparation, review, and approval of the manuscript.

\section{Compliance with ethical standards}

Conflict of interest The authors declare they that have no conflicts of interest relevant to this report, and no financial conflicts related to the topic.

Ethical approval The trial was approved by the Ethics Committee of Helsinki University Central Hospital, and the procedures were planned in accordance with the Declaration of Helsinki. Each participating resident and her/his closest proxy were provided with detailed information both orally and in writing, and they gave their informed consent. In cases of moderate-to-severe dementia, the proxy gave the consent on behalf of the resident. The study was registered in the Australian New Zealand Clinical Trials Registry under the intervention code: ACTRN12617001040358.
Open Access This article is distributed under the terms of the Creative Commons Attribution 4.0 International License (http://creativeco mmons.org/licenses/by/4.0/), which permits unrestricted use, distribution, and reproduction in any medium, provided you give appropriate credit to the original author(s) and the source, provide a link to the Creative Commons license, and indicate if changes were made.

\section{References}

1. Mitchell SL, Teno JM, Kiely DK, Shaffer ML, Jones RN, Prigerson HG, Volicer L, Givens JL, Hamel MB (2009) The clinical course of advanced dementia. N Engl J Med 361:1529-1538

2. Singer AE, Goebel JR, Kim YS et al (2016) Populations and interventions for palliative and end-of-life care: a systematic review. J Palliat Med 19:995-1008

3. Robinson L, Dickinson C, Rousseau N, Beyer F, Clark A, Hughes J, Howel D, Exley C (2012) A systematic review of the effectiveness of advance care planning interventions for people with cognitive impairment and dementia. Age Ageing 41:263-269

4. Houben CHM, Spruit MA, Groenen MTJ, Wouters EFM, Janssen DJA (2014) Efficacy of advance care planning: a systematic review and meta-analysis. J Am Med Dir Assoc 15:477-489

5. Molloy DW, Guyatt GH, Russo R et al (2000) Systematic implementation of an advance directive program in nursing homes: a randomized controlled trial. JAMA 283:1437-1444

6. Casarett D, Karlawish J, Morales K, Crowley R, Mirsch T, Asch DA (2005) Improving the use of hospice services in nursing homes: a randomized controlled trial. JAMA 294:211-217

7. Kane RL, Keckhafer G, Flood S, Bershadsky B, Siadaty MS (2003) The effect of evercare on hospital use. J Am Geriatr Soc 51:1427-1434

8. Hanson LC, Reynolds KS, Henderson M, Pickard CG (2005) A quality improvement intervention to increase palliative care in nursing homes. J Palliat Med 8:576-584

9. Morrison RS, Chichin E, Carter J, Burack O, Lantz M, Meier DE (2005) The effect of a social work intervention to enhance advance care planning documentation in the nursing home. J Am Geriatr Soc 53:290-294

10. Givens JL, Jones RN, Shaffer ML, Kiely DK, Mitchell SL (2010) Survival and comfort after treatment of pneumonia in advanced dementia. Arch Intern Med 170:1102-1107 
11. Givens JL, Selby K, Goldfeld KS, Mitchell SL (2012) Hospital transfers of nursing home residents with advanced dementia. J Am Geriatr Soc 60:905-909

12. Gozalo P, Teno JM, Mitchell SL, Skinner J, Bynum J, Tyler D, Mor V (2011) End-of-life transitions among nursing home residents with cognitive issues. N Engl J Med 365:1212-1221

13. Dwyer R, Gabbe B, Stoelwinder JU, Lowthian J (2014) A systematic review of outcomes following emergency transfer to hospital for residents of aged care facilities. Age Ageing 43:759-766

14. Aaltonen M, Forma L, Rissanen P, Raitanen J, Jylha M (2010) Transitions in health and social service system at the end of life. Eur J Ageing 7:91-100

15. Vandervoort A, Houttekier D, Vander Stichele R, van der Steen JT, den Van Block L (2014) Quality of dying in nursing home residents dying with dementia: does advanced care planning matter? A nationwide postmortem study. PLoS One 9:e91130

16. Flo E, Husebo BS, Bruusgaard P, Gjerberg E, Thoresen L, Lillemoen L, Pedersen R (2016) A review of the implementation and research strategies of advance care planning in nursing homes. BMC Geriatr 16:4

17. Caplan GA, Meller A, Squires B, Chan S, Willett W (2006) Advance care planning and hospital in the nursing home. Age Ageing 35:581-585

18. Connolly MJ, Boyd MNP, Broad JBBA, Kerse NM, Lumley T, Whitehead N, Foster SMSW (2015) The Aged Residential Care Healthcare Utilization Study (ARCHUS): a multidisciplinary, cluster randomized controlled trial designed to reduce acute avoidable hospitalizations from long-term care facilities. J Am Med Dir Assoc 16:49-55

19. Ouslander JG, Perloe M, Givens JH, Kluge L, Rutland T, Lamb G (2009) Reducing potentially avoidable hospitalizations of nursing home residents: results of a pilot quality improvement project. J Am Med Dir Assoc 10:644-652

20. Tena-Nelson R, Santos K, Weingast E, Amrhein S, Ouslander J, Boockvar K (2012) Reducing potentially preventable hospital transfers: results from a thirty nursing home collaborative. J Am Med Dir Assoc 13:651-656

21. Ouslander JG, Lamb G, Tappen R, Herndon L, Diaz S, Roos BA, Grabowski DC, Bonner A (2011) Interventions to reduce hospitalizations from nursing homes: evaluation of the INTERACT II Collaborative Quality Improvement Project. J Am Geriatr Soc 59:745-753

22. Kane RL, Huckfeldt P, Tappen R, Engstrom G, Rojido C, Newman D, Yang Z, Ouslander JG (2017) Effects of an Intervention to Reduce Hospitalizations From Nursing Homes. JAMA Intern Med 177:1257

23. Anstey S, Powell T, Coles B, Hale R, Gould D (2016) Education and training to enhance end-of-life care for nursing home staff: a systematic literature review. BMJ Support Palliat Care 6:353-361

24. Hawes C, Morris JN, Phillips CD, Fries BE, Murphy K, Mor V (1997) Development of the nursing home Resident Assessment Instrument in the USA. Age Ageing 26(Suppl 2):19-25

25. Charlson ME, Pompei P, Ales KL, MacKenzie CR (1987) A new method of classifying prognostic comorbidity in longitudinal studies: development and validation. J Chronic Dis 40:373-383

26. Hughes CP, Berg L, Danziger WL, Coben LA, Martin RL (1982) A new clinical scale for the staging of dementia. Br J Psychiatry J Ment Sci 140:566-572

27. Folstein MF, Folstein SE, McHugh PR (1975) "Mini-mental state": a practical method for grading the cognitive state of patients for the clinician. J Psychiatr Res 12:189-198

28. Guigoz Y, Lauque S, Vellas BJ (2002) Identifying the elderly at risk for malnutrition. The Mini Nutritional Assessment. Clin Geriatr Med 18:737-757
29. WHO Collaborating Centre for Drug Statistics Methodology Anatomical therapeutic chemical classification system. ATC/DDD Index 2018. https://www.whocc.no/atc_ddd_index/. Accessed 1 Nov 2018

30. Jansen K, Haugen DF, Pont L, Ruths S (2018) Safety and effectiveness of palliative drug treatment in the last days of life-a systematic literature review. J Pain Symptom Manage 55:521.e3

31. Bruera E, Kuehn N, Miller MJ, Selmser P, Macmillan K (1991) The Edmonton Symptom Assessment System (ESAS): a simple method for the assessment of palliative care patients. J Palliat Care 7:6-9

32. Warden V, Hurley AC, Volicer L (2003) Development and psychometric evaluation of the Pain Assessment in Advanced Dementia (PAINAD) scale. J Am Med Dir Assoc 4:9-15

33. Sintonen H, Pekurinen M (1993) A fifteen-dimensional measure of health-related quality of life (15D) and its applications. In: Walker SR, Rosser RM (eds) Quality of life assessment: key lisues in the 1990s. Springer, Dordrecht, pp 185-195

34. Pitkala KH, Juola AL, Kautiainen H, Soini H, Finne-Soveri UH, Bell JS, Bjorkman M (2014) Education to reduce potentially harmful medication use among residents of assisted living facilities: a randomized controlled trial. J Am Med Dir Assoc 15:892-898

35. Routasalo PE, Tilvis RS, Kautiainen H, Pitkala KH (2009) Effects of psychosocial group rehabilitation on social functioning, loneliness and well-being of lonely, older people: randomized controlled trial. J Adv Nurs 65:297-305

36. Kiely DK, Shaffer ML, Mitchell SL (2012) Scales for the evaluation of end-of-life care in advanced dementia: sensitivity to change. Alzheimer Dis Assoc Disord 26:358-363

37. Knowles, MS (1980) The modern practice of adult education: from pedagogy to andragogy. Cambridge, The Adult Education Co., New York, NY

38. Kolb DA (1984) Experiential learning : experience as the source of learning and development. Prentice-Hall, Upper Saddle River

39. Dolmans DH, De Grave W, Wolfhagen $\mathrm{IH}$, van der Vleuten $\mathrm{CP}$ (2005) Problem-based learning: future challenges for educational practice and research. Med Educ 39:732-741

40. De Corte E (2003) Powerful learning environments: Unravelling basic components and dimensions. Pergamon/Elsevier Science Ltd, Oxford

41. Van Buuren S, Oudshoorn K (1999) Flexible mutlivariate imputation by MICE. TNO, Leiden

42. Royston P (2005) Multiple imputation of missing values: update of ice. Stata J 5:527

43. Abrahamson K, Mueller C, Davila HW, Arling G (2014) Nurses as boundary-spanners in reducing avoidable hospitalizations among nursing home residents. Res Gerontol Nurs 7:235-243

44. Lopez RP (2009) Decision-making for acutely ill nursing home residents: nurses in the middle. J Adv Nurs 65:1001-1009

45. Laging B, Ford R, Bauer M, Nay R (2015) A meta-synthesis of factors influencing nursing home staff decisions to transfer residents to hospital. J Adv Nurs 71:2224-2236

46. Pitkala KH, Blomquist L, Routasalo P, Saarenheimo M, Karvinen E, Oikarinen U, Mantyranta T (2004) Leading groups of older people: A description and evaluation of the education of professionals. Educ Gerontol. https://doi.org/10.1080/036012704905072 68

Publisher's Note Springer Nature remains neutral with regard to jurisdictional claims in published maps and institutional affiliations. 